\title{
The Analysis of Several Chinese Cultural Symbols in Chinese-American Literature
}

\author{
Jingbo Zhu \\ Qiqihar Medical University, Hei Longjiang Province, China
}

\begin{abstract}
Keywords: Chinese cultural symbol, Chinese-American literature, Cultural crash, Cultural convergence.
\end{abstract}

\begin{abstract}
Today, Chinese-American works have already become an important aspect of American literature and culture. The thesis is an attempt to analyze several Chinese cultural symbols in some famous Chinese-American works. The representation of these symbols is an implication to show these writers' cultural identity, from cultural clash to cultural convergence at last.
\end{abstract}

\section{Introduction}

Cultural symbols refer to those symbols with strong cultural attributes and cultural connotations. It can represent some certain kind of concept, humanistic sensibility and value orientation after being penetrated by stream of time and tested by our daily life. Cultural symbols can be a kind of material, someone derived from historical legends and folk stories, and some kind of widespread customs or beliefs, such as "Faust" and "Carnival" in the European culture, "Japanese flowering cherry" in the Japanese culture, "Dragon" and "Ghost" in the Chinese culture. Therefore, Chinese cultural symbols refer to those that can represent traditional Chinese cultural values and connotations. In Chinese-American works, the widespread existence of Chinese cultural symbols gives us symbolic function. When using these Chinese cultural symbols, many Chinese-American writers change their traditional implications. They intend to reflect Chinese American experience and thoughts, rather than Chinese pride and glory. The thesis analyzes several Chinese cultural symbols in order to show the hard process from cultural clash to cultural convergence which Chinese-American writers struggle to overcome.

\section{Ghost—Dilemma of Cultural Identity}

"Ghost" derives from individual's conjecture and speculation in the life and afterlife from the aspect of cultural psychology. This is one sort of spiritual sustenance to Chinese for their belief of karma. Chinese scattered people sailed across the ocean after innumerable hardships to go to American Chinatown, "Ghost", as one part of Chinese cultural symbol, came with them and became one branch of Chinatown's culture. With the implementation of "melting pot" cultural policies in American society and the Chinese descendants born in the host country becoming the main element of the Chinese community, this cultural symbol, "Ghost”, has possessed more plentiful and various implications.

In Maxine Hong Kingston's The Woman Warrior, one of narrators "I" has grown up with mother's telling ghost stories which has become an important channel to help me comprehend Chinese culture, and then my mother has become spokesperson of traditional Chinese culture. The behavior that the mother told her daughter ghost stories lets the daughter be familiar with Chinese traditional culture. At the same tome, "I" have been haunted by these ghost stories for many years. However, after growing up, "Ghost" has turned into a manifestation of deep-rooted bad habits in traditional Chinese culture.

"Ghost" is terrifying and frightening in traditional Chinese culture. The first-generation Chinese American intend to call the white American "ghost" in an attempt to prevent their kids from being influenced by American culture for they want their kids only to know Chinese culture. They believe it is Chinese culture that can make their children grow healthily and achieve essential identity about 
Chinese values, so their children can maintain and inherit the Chinese Culture consequently.

We can find the constant reference of different images about "Ghost" in The Woman Warrior. On one hand, "Ghost" is not only the representation of traditional Chinese culture that the mother attempted to instill into the daughter's mind but also the daughter's carrier for imagination to Chinese culture. On the other hand, "Ghost" is a symbol of racial discrimination suffered by the Chinese ethnic group, and the poetic expression of bitter experience which the Chinese ethnic group has gone through from the edge to the center in the United States. The double connotations of the "Ghost" image indicate Chinese American struggled inner feelings for their double background and dual identity, and their hardships, bitterness, confusion and sense of homelessness as they have to wring a life in Chinese and American.

Through the image of "Ghost", the author truly intends to express the crash of two heterogeneous cultures leads to Chinese descendants' tension and contradiction in identity, and the hardships they have to experience when two cultures integrating from conflict to harmony. In The Woman Warrior, these ghost stories make "I" acknowledge my own identity and understand traditional Chinese culture in a new aspect. Therefore, the two cultures have integrated from conflict to harmony at last.

\section{Tea-Cure of Cultural disease}

China is the hometown of tea. Tea has become an important medium for entertaining guests and social interaction. In addition, tea is still an effective drug. Therefore, tea has become a vital component of Chinese folklore because of its significant value. Especially after poets and literary men's extolment, tea has been distinct representation of Chinese cultural symbol. In Chinese-American works, "tea" is an important symbol which possesses diverse and plentiful symbolic meaning.

In Louis Chu Eat a Bowl of Tea, the narration of "tea" appears many times. It not only promotes the development of the story, but also participates in the shape of the character, and even affect the outcome of the story. We can find the consistent influence of "tea" from the marriage between the hero Wang Binlai and his wife. In their wedding, the bride serves tea to the guests, and then relatives and friends put the money on the tea tray to the newlyweds. In the foreign land, it is commendable for young Binlai to make his own real interests by applying traditional Chinese custom. "tea" has been the essential medium to strengthen family, friendship and love, and the concentrated embodiment of traditional Chinese ethics.

From this point of view, "tea" has a powerful ability to adapt and survive in the foreign land as a significant part of Chinese culture. Even in the indifferent American society advocating "fast food culture", "tea” culture has still been inherited and preserved by several teahouses in Chinatown. "Tea" and traditional Chinese ethics represented by it has achieved continuation and become an essential emotional medium to communicate between the two generations of Chinese American. This is its first metaphor in the novel.

In this novel, there is another detail deserving our attention. The hero Binlai has sexual dysfunction. After several useless attempts of western medicine treatment, the couple have to turn to traditional Chinese medicine in Chinatown. At last, Binlai's disease has been cured successfully. The cure of his disease by Chinese herbal tea indicates powerful metaphorical meaning. In fact, Binlai's sexual dysfunction is metaphor to depict the agonizing fact that Chinese had been "castrated" in the past 100 years. The author hopes to illustrate that male Chinese essential feature can be restored only by resorting to traditional Chinese cultural values (mainly heirs and "filial piety" concept) through the narration of the cure to Binlai's chronic illness by Chinese herbal tea. Then the history of Chinese descent can be restored, male Chinese will be thrived afterwards. This is the second metaphor in the novel.

Similarly, in Tea That Burns written by Bruce Edward Hall, Chinese descendants applies traditional Chinese teapot openly drink spirits being prohibited by American law in a period of probation against alcoholic drinks in the United States, which is a typical case about the evolution of Chinese tea culture in the foreign land. This simple innovation, putting spirits into teapot, not 
only indicates the continuation of traditional Chinese culture revealed in Chinese American, but also reflects Chinese living environment in a foreign country. Chinese cultural identity is just like this teapot of spirits, integrating the ancient Chinese culture with American community culture closely.

\section{Kuan Kung-Restoration of Chinese Heroism}

Kuan Kung is an important character in Chinese classical novel Three Kingdoms. Through the widespread of folk and official propaganda, Kuan Kung has been an essential component of Chinese culture and an inseparable part of Chinese ethnic memory. In addition, loyalty has endowed Kuan Kung with great attraction to Chinese-American writers, and his male temperament coincides with Chinese-American writers' attempt to restore Chinese heroic tradition. In his work Chinatown, Lin Yutang depicted that Kuan Kung was a military model in Chinese history, becoming Mars after death, which protected honest persons and condemn cruel, dishonest persons.

In Frank Chin's Gunga Din Highway, Kuan Kung represents loyalty, heroism, integrity, and the embodiment of great Chinese character. He calls second-generation Chinese immigrants "Ulysses Kuan", which shows his all hopes to construct Chinese-American identity. "Ulysses” in Greek mythology is courageous, firm and intelligent, cunning and full of spirit of adventure; besides, Kuan Kung in traditional Chinese legend is heroic, loyal and a superb martial artist. Frank Chin desires to restore and establish traditional Chinese heroism by integrating the two heroic characters representing Chinese and Western heroic tradition respectively.

As one of traditional Chinese culture symbols, the connotation of Kuan Kung has consistently become rich. According to Chinese-American perspective, the image of Kuan Kung can assist Chinese-American to overcome racial discrimination and achieve power to survive tenaciously in rough environment. More importantly, this image promotes Chinese-American writers break the silence and gain the power of discourse. Through the image of Kuan Kung, Chinese-American writers claim the first appeal against racial discrimination and "castration", digest stereotype to male Chinese in American mainstream society and restore Chinese heroic tradition.

\section{Qu Yuan-Elegy of Cultural Exile}

Qu Yuan, the Chinese cultural symbol, first appearing in The Songs of Chu, depicts an ancient official loyal to his sovereign who was born at the wrong times, cared for the fate of his nation and died for his motherland jumping into the Miluo River.

In Chinaman, Maxine Hong Kingston borrows this Chinese cultural symbol, Qu Yuan. The exiling experience of $\mathrm{Qu}$ Yuan seems to be similar to early Chinese-American struggles and the symbolization of early Chinese-American rough life and pioneering spirit. Through the image of Qu Yuan, the author retrospects Chinese-American suffering, depicts Chinese-American struggling between these two cultures, and establishes the figure of exile in cultural sense.

The second Chinese-American hopes to set down root in America. However, when they are passionate to complete their beautiful dreams to be integrated into American society, the truth of indifferent American society lets them feel totally lost. They intend to change their identity in American "melting pot", but their racial characteristic-yellow skin-cannot make them completely become American. Chinese-American writers have succeeded in shaping the figure of cultural exile. There is still a long way to go for them to find their identity positioning conforming reality and finish this cultural exile state completely.

The application of Chinese cultural symbols in Chinese-American works is of great significance. On one hand, it assists these Chinese-American writers who lack of living experience in Chinese mainland to build Chinese cultural context. It also lets Chinese-American literature achieve self-fashioning from actual and spiritual aspect. On the other hand, the application of Chinese mythology and folklore represents a special way for Chinese-American writers to identify Chinese culture. They will actively combine Chinese cultural sources with American ones, difference between reality and cultural ideal, which is beneficial enlightenment to description in global context and cultural exchanges. 
The description in Chinese-American works demonstrates that traditional Chinese culture possesses permanent vitality although experienced thousands of years. Moreover, the cultural heritage shows unprecedented enormous energy today. Many nations have soberly recognized that maintaining their own national culture is the only way to successfully go to the world in today's world integration. Each nation is not supposed to give up their traditional culture, but makes it obtain consistent replacement and development, actively participating in the whole world cultural communication. In the foreseeable global landscape, each national cultural custom will not lose her identity, but participate in the world integration with her irreplaceable individuality, constituting a harmonious world according to the principle of equal treatment and mutual respect.

\section{Acknowledgements}

Project of the Social Science Funds of Qiqihar Medical University, Project Number : QYSKL2015-14

\section{References}

[1] Yin Xiaohuang, Chinese American Literature since the 1850s [M]. Urbana: University of Illinois Press. c 2000.

[2] Frank Chin, Jeffery Paul Chan, Lawson Fusao Inada, and Shawn Wong, Aiiieeeee!: An Anthology of Asian American Writers [G]. Washington, D. C.: Howard University Press. 1974.

[3] Bassnett. \& Lefevere, A Constructing Cultures [M]. Shanghai: Shanghai Foreign Language Education Press. 2001.

[4] Louis Chu, Eat a Bowl of Tea[M]. Carol Publishing Group Edition, 1995.

[5] Maxine Hong Kingston, The Woman Warrior: Memories of a Girlhood Among Ghosts [M]. New York: Vintage Books, 1989. 